Antonio Espuña, Moisès Graells and Luis Puigjaner (Editors), Proceedings of the $27^{\text {th }}$ European Symposium on Computer Aided Process Engineering - ESCAPE 27

October $1^{\text {st }}-5^{\text {th }}, 2017$,Barcelona, Spain $\odot 2017$ Elsevier B.V. All rights reserved.

\title{
Model-Based Analysis and Integration of Synthetic Methane Production and Methane Oxidative Coupling
}

\author{
Estelle le Saché, ${ }^{a}$ Yang Peng, ${ }^{a}$ Harvey Arellano-Garcia, ${ }^{a *}$ Tomas Ramirez \\ Reina ${ }^{\text {a* }}$ \\ ${ }^{a}$ Department of Chemical and Process Engineering, Faculty of Engineering and \\ Physical Sciences, University of Surrey, Guildford, GU2 7XH, United Kingdom \\ t.ramirezreina@surrey.ac.uk; h.arellano-garcia@surrey.ac.uk
}

\begin{abstract}
Ethylene is the world's largest commodity chemical and a fundamental building block molecule in the chemical industry. Oxidative coupling of methane (OCM) is considered a promising route to obtain ethylene due to the potential of natural gas as a relatively economical feedstock. In a recent work, this route has been integrated by Godini et al (2013) with methane dry reforming (DRM) in a dual membrane reactor, allowing an improved thermal performance.

In this work, we have explored a more ambitious integrated system by coupling the production of methane and carbon dioxide via coal gasification with the DRM-OCM unit. Briefly, our process utilises coal to generate value-added methane and ethylene. In addition, $\mathrm{CO}_{2}$ management is achieved through $\mathrm{CO}_{2}$ methanation and dry methane reforming. Potential mass and energy integration between two systems is proposed as well as the optimum conditions for synthetic natural gas production. The upstream gasification process is modelled to determine the influence of temperature, pressure, and feed composition in the methane yield. The results suggest that the key variables are temperature and hydrogen concentration, as both parameters significantly affect the methane and $\mathrm{CO}_{2}$ levels in the linking stream. This study reports for the first time the linking stream between the two systems with a high methane concentration and the appropriate amount of $\mathrm{CO}_{2}$ for downstream processing.
\end{abstract}

Keywords: methanation, oxidative coupling of methane, dry reforming, process integration, gasification.

\section{Introduction}

Ethylene is a fundamental molecule for the chemical industry. It is widely used in the synthesis of numerous chemicals and is therefore a high value hydrocarbon. In 2016, ethylene was the most produced organic compound, with over 150 million tonnes synthesised. Ethylene production via the oxidative coupling of methane (OCM) process has been studied and developed over the past 30 years (P. Graf, 2008). One of the most promising process integration is the complementary use of the carbon dioxide methane reforming (DRM) process and the OCM process through a novel reactor configuration: the dual membrane reactor proposed by Godini et al (2013). In this design, oxygen is diffused through a porous membrane to the OCM section, as it is passing through the 


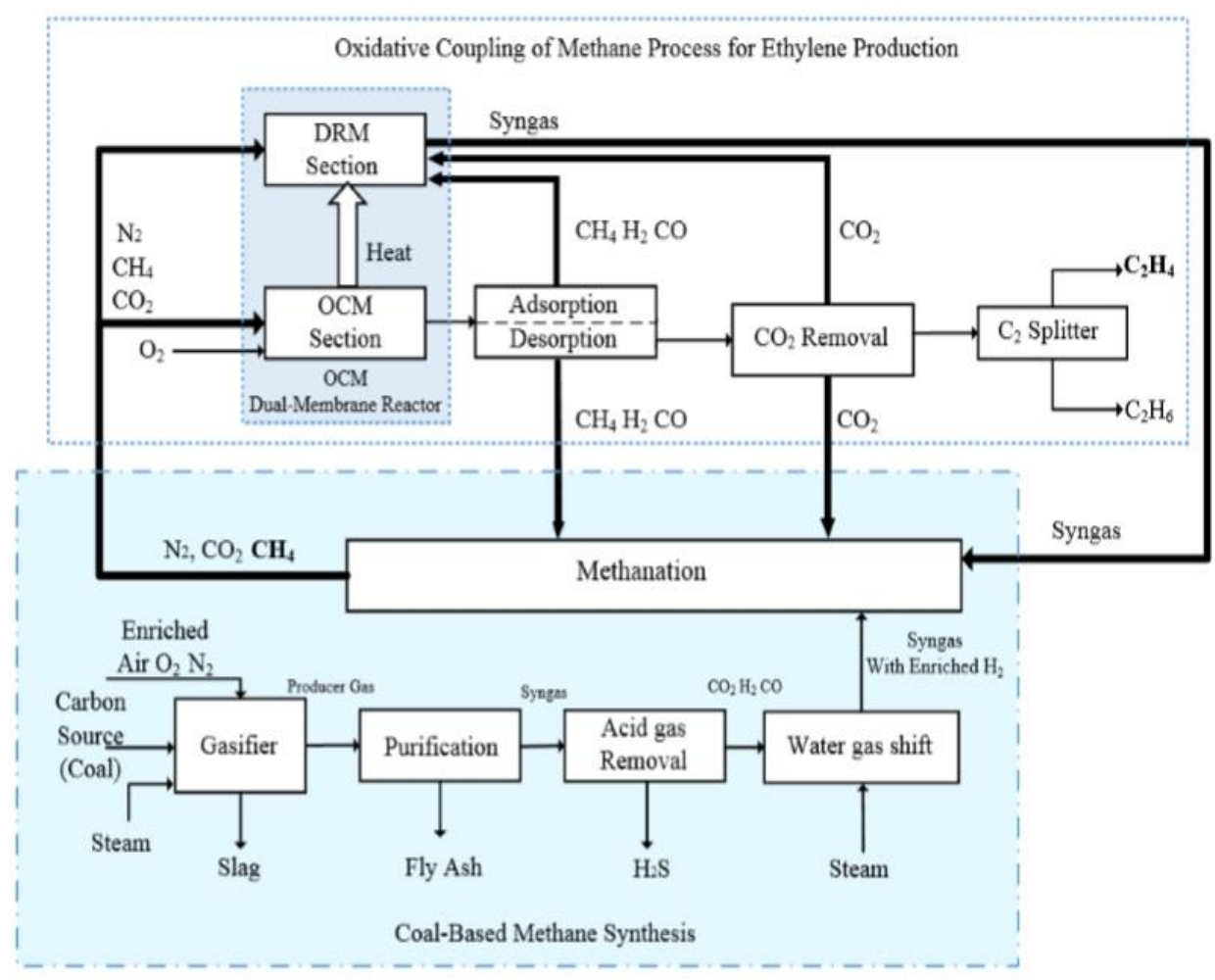

Figure 1.Conceptual Process Integration of Coal based Methanation and Oxidative Coupling of Methane.

centre of the reactor. The $\mathrm{CO}_{2}$ produced is transferred through a selective membrane and consumed in the adjacent dry methane reforming catalytic bed. The energy integration in the OCM reactor is achieved when the DRM process acts as a heat sink and reduces the OCM reaction temperature, therefore improving the heat integration efficiency. This new process improved both $\mathrm{C} 2$ selectivity and $\mathrm{C} 2$ yield (Godini et al, 2014), but is sensitive to the $\mathrm{CO}_{2}$ concentration at the inlet.

Coal being one of the cheapest and most abundant energy resources, synthetic methane produced from coal based gasification is an attractive substitute for natural gas. It is considered to be a way of purifying solid fuels. The integration of coal based methanation process with the OCM reactor may be an ultimate solution to ease the environmental impact induced by the process. The $\mathrm{CO}_{2}$ produced in the process can be recycled as reactant in the methanation and the dry reforming processes. Figure 1 represents a conceptual process design of the two integrated system. Potential mass integrations are marked in bold. Water removal is introduced after both methanation and OCM reactors. The main focus of this work is to optimise the linking stream between the methanation reactor and the dual membrane reactor. The composition of the linking stream must be optimised by adjusting the upstream process conditions to satisfy the reaction specification of the downstream route. In this scenario, the main target is to ensure a high methane yield to feed the dual-membrane reactor and to improve the $\mathrm{CO}_{2}$ management across the integrated system. 


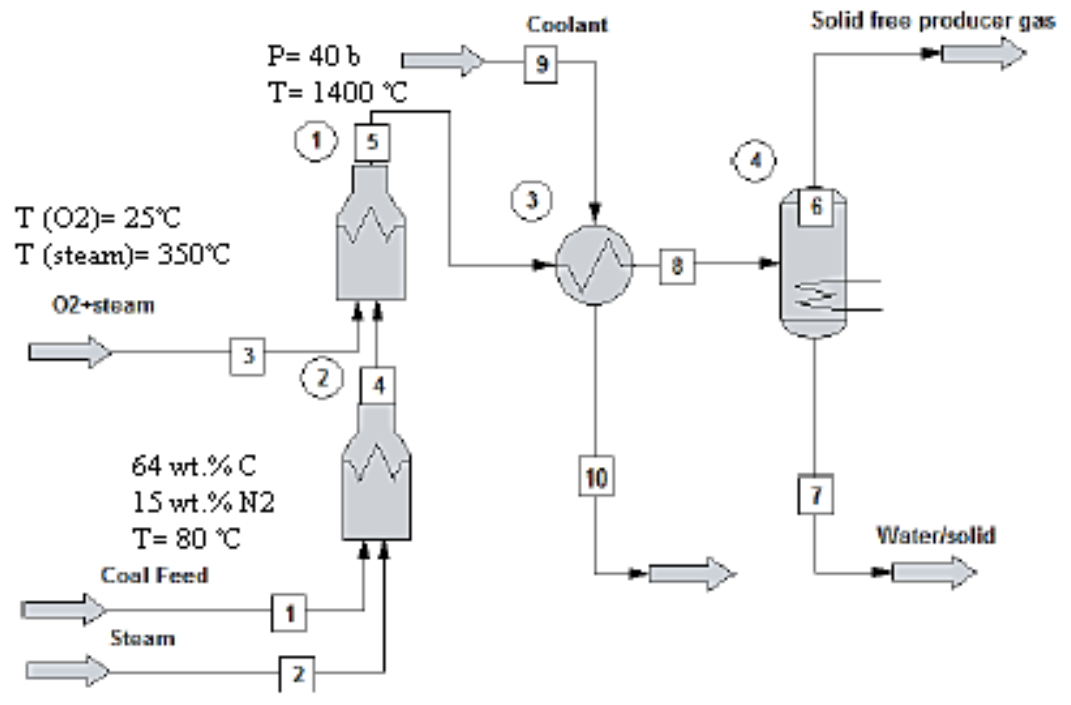

Figure 2.ChemCAD setup for gasification and purification.

\section{Model construction}

The model of the gasification process was carried out using both ChemCAD and Aspen HYSYS and selecting the SRK thermodynamic package. Although initially we planned to simulate the entire process in Aspen HYSYS, we finally selected ChemCAD for the gasification unit due to its suitability to deal with solid compounds. Figure 2 pictures the ChemCAD setup of the first part of the simulation: gasification and solid separation. In the simulation, the coal fed to the gasification reactor consisted of $64 \mathrm{wt} . \%$ carbon. The coal, steam, oxygen ratio was 1:0.7:1 and nitrogen was introduced as carrier gas for granulated coal. GIBBS combustion reactors were selected as gasifier, as the reactor model is specified based on the principle of minimizing the Gibbs free energy, which has

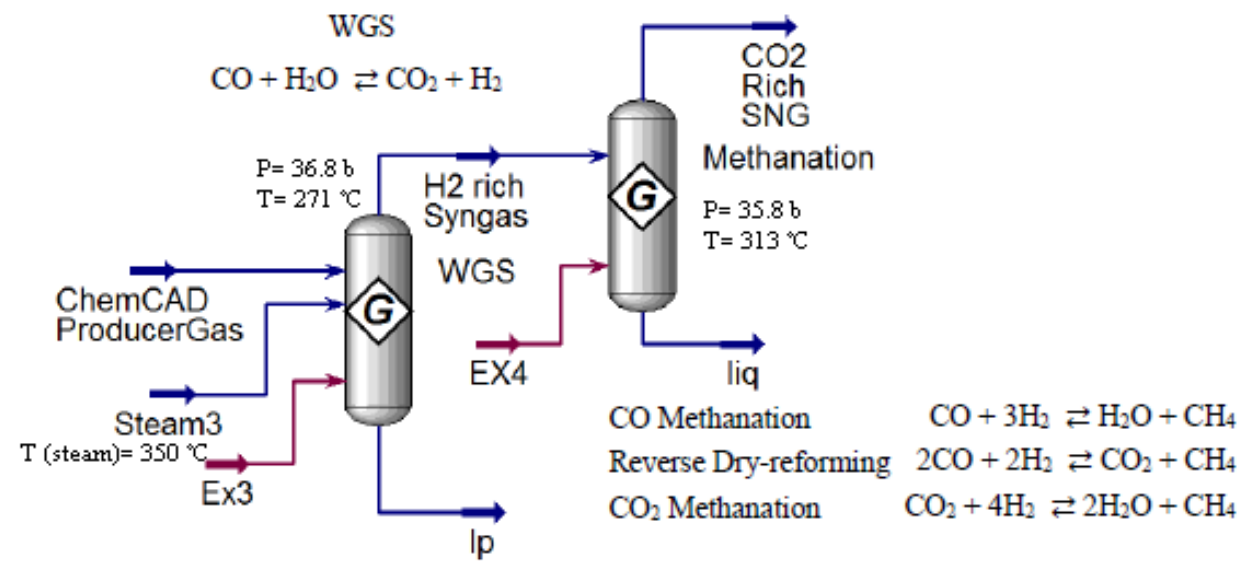

Figure 3.Simulation set up for WGS and methanation in Aspen HYSYS 
been widely used in coal gasification process simulations (Y. Zhu et al, 2015). The raw producer gas stream was cooled prior the purification processes, then filtered and passed through a water quench tower to remove any remaining ash. Sulphur-containing compounds were eliminated in the acid gas removal units. Carbon dioxide was remained in the system since it was required for sensitivity studies of the later stages of the process.

Next part of the simulation was conducted in Aspen HYSYS (Figure 3). The Water Gas Shift reaction (WGS) along with the CO methanation reaction were considered to happen in the WGS reactor. Although in the shift reactor the methanation process is not specially favored. As in the methanation reactor, WGS, $\mathrm{CO}$ methanation, reverse DRM, $\mathrm{CO}_{2}$ methanation and the Boudouard reaction were set to occur. The composition of products streams are listed in Table 1.

Table 1. Molar compositions after each major process across the system.

\begin{tabular}{ccc|cc}
\hline & \multicolumn{2}{c|}{ ChemCAD } & \multicolumn{2}{c}{ HYSYS } \\
\hline $\begin{array}{c}\text { Molar } \\
\text { fraction }\end{array}$ & $\begin{array}{c}\text { Raw Producer } \\
\text { Gas }\end{array}$ & $\begin{array}{c}\text { Clean } \\
\text { Producer Gas }\end{array}$ & After WGS & $\begin{array}{c}\text { After } \\
\text { Methanation }\end{array}$ \\
\hline $\mathrm{CH}_{4}$ & Trace & Trace & Trace & 0.308 \\
$\mathrm{H}_{2} \mathrm{O}$ & 0.088 & & 0.004 & 0.148 \\
$\mathrm{H}_{2}$ & 0.340 & 0.379 & 0.470 & 0.003 \\
$\mathrm{CO}$ & 0.468 & 0.522 & 0.294 & Trace \\
$\mathrm{CO}_{2}$ & 0.036 & 0.040 & 0.183 & 0.462 \\
$\mathrm{O}_{2}$ & Trace & Trace & Trace & Trace \\
$\mathrm{N}_{2}$ & 0.051 & 0.057 & 0.048 & 0.078 \\
$\mathrm{C}$ & 0.001 & & & \\
$\mathrm{~S}$ & 0.002 & 0.003 & & \\
$\mathrm{SO}{ }_{2}$ & $105(\mathrm{ppm})$ & $105(\mathrm{ppm})$ & Trace & Trace \\
$\mathrm{SiO} 2$ & 0.011 & & & \\
$\mathrm{CaO}_{2}$ & 0.002 & & & \\
$\mathrm{CH}_{4}$ Dry \% & - & - & - & 36.16 \\
$\mathrm{H}_{2}$ Dry \% & 37.25 & 37.86 & 47.253 & 0.37 \\
$\mathrm{CO}_{\text {Dry } \%}$ & 51.36 & 52.20 & 29.534 & 0.03 \\
$\mathrm{CO}_{2}$ Dry \% & 3.91 & 3.97 & 18.361 & 54.27 \\
$\mathrm{H}_{2} / \mathrm{CO}_{\text {ratio }}$ & - & 0.725 & 1.600 & - \\
\hline
\end{tabular}

\section{Sensitivity Analysis}

Multiple sensitivity analysis were carried out, focusing on the WGS and methanation processes. First the effect of temperature and pressure were studied on the methanation process (Figure 4). The trends confirm that the optimum operating condition for a methanation reactor is at high pressure and low temperature. The main reactions involved in the process are CO hydrogenation and reverse DRM, two very exothermic reactions and hence favoured at lower temperatures.

The pressure sensitivity test was performed at different temperatures. Methane production is greater at high pressure, in accordance with the stoichiometry of the reactions involved. However, the simulation results suggested that the pressure only has a noticeable effect on the methane yield when the operating temperature is over $400{ }^{\circ} \mathrm{C}$. The temperature influence on the reactor performance seems to be significantly greater than the effect of the pressure. 

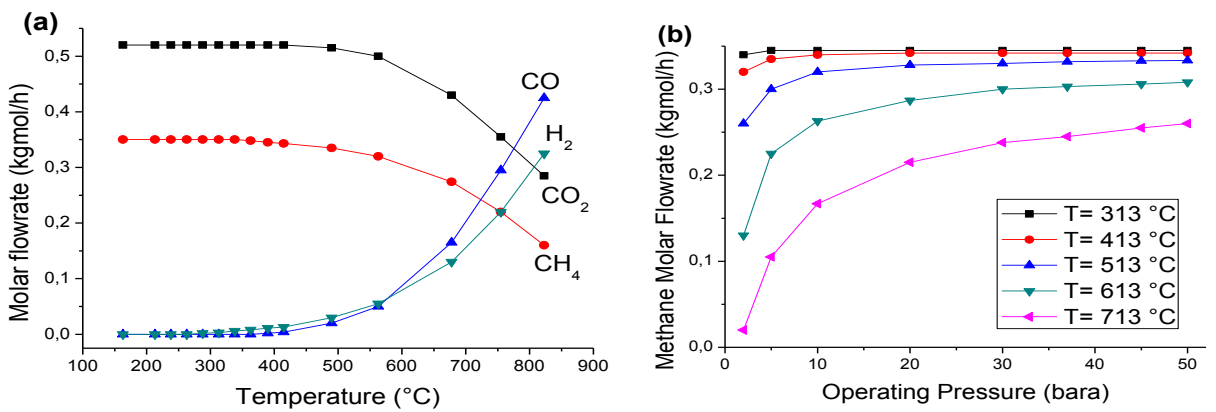

Figure 4. Temperature and Pressure effect on the methanation process

(a) Temperature effect on the outlet composition (b) Pressure effect on the production of $\mathrm{CH}_{4}$

Further insights were obtained from the sensitivity studies of temperature and pressure in the WGS reactor. The results suggested the operating pressure has no influence on the reaction equilibrium, however higher $\mathrm{CO}$ conversion is achieved at low temperature in good agreement with the exothermic character of the reaction. It should be noticed that the highest $\mathrm{H}_{2} / \mathrm{CO}$ ratio achieved under the studied conditions was 1.6.

The effect of $\mathrm{CO}_{2}$ on the methanation reactor performance was also studied. Tests were carried out over a range of temperatures (Figure $5 \mathrm{a}$ ). All of the studies were performed at constant $\mathrm{CO}, \mathrm{H}_{2}$ and steam inputs with identical equilibrium reaction specifications. The implemented $\mathrm{H}_{2} / \mathrm{CO}$ ratio was 1.6 according to the maximum $\mathrm{H}_{2} / \mathrm{CO}$ ratio derived from the shift reactor sensitivity analysis. Usually $\mathrm{CO}_{2}$ is removed prior the WGS and Methanation processes, to prevent any shift of the reaction equilibrium towards the reactants. However, when methane is the targeted product, the $\mathrm{CO}_{2}$ hydrogenation could certainly contribute to boost the methane yields and therefore in our approach $\mathrm{CO}_{2}$ is not withdrawn before feeding the methanation reactor. Indeed, the efficiency of $\mathrm{CO}_{2}$ utilisation is another key aspect in the proposed coupled system. As for CO hydrogenation, $\mathrm{CO}_{2}$ hydrogenation is favoured at low temperature and high pressure. However, it is still less exothermic than $\mathrm{CO}$ hydrogenation. Therefore, the optimum temperature of $\mathrm{CO}_{2}$ hydrogenation is predicted to be slightly higher than $\mathrm{CO}$ hydrogenation, at a constant pressure. In Figure 5a, results show that $\mathrm{CO}_{2}$ had only an impact on the methane production above $500{ }^{\circ} \mathrm{C}$, where an increase is $\mathrm{CO}_{2}$ content improves the methane synthesis. However, the reaction temperature is still the governing parameter.
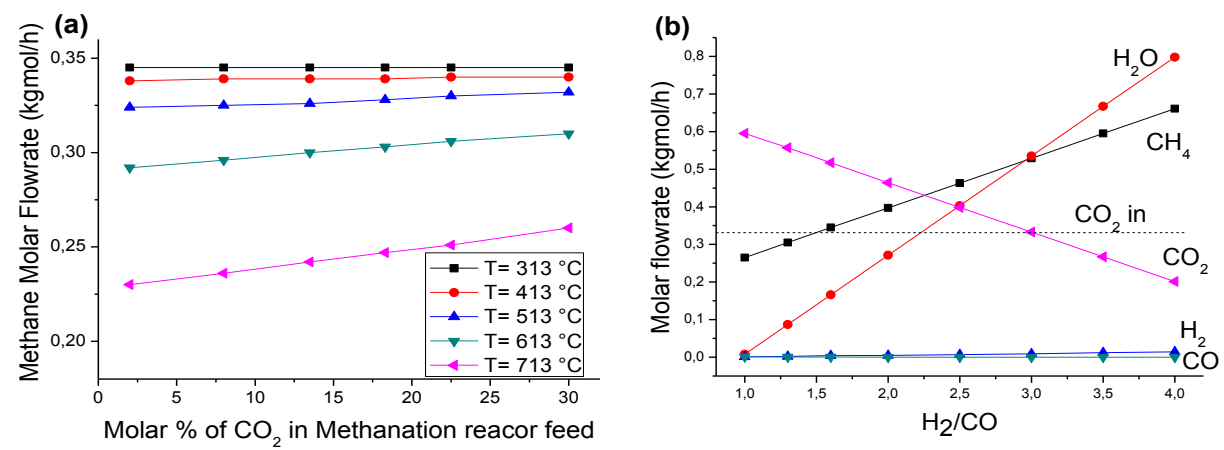

Figure 5.(a) $\mathrm{CO}_{2}$ effect on methane production (b) $\mathrm{H}_{2}$ effect on product distribution 
The effect of the quantity of hydrogen in the feed stream has been studied (Figure 5b).Interestingly, there is the direct connection between the feed hydrogen concentration and the production of methane. Besides, the overall trend of the components in the product flow reveals the reactions occurring in the methanation reactor. Prior to the reactor, $\mathrm{CO}$ and $\mathrm{CO}_{2}$ flow rates were $0.532 \mathrm{kggmol} / \mathrm{h}$ and $0.330 \mathrm{kggmol} / \mathrm{h}$, respectively. $\mathrm{CO}$ is entirely consumed at low hydrogen concentration to produce methane, water and $\mathrm{CO}_{2}$. As the $\mathrm{H}_{2} / \mathrm{CO}$ ratio increase, the $\mathrm{CO}_{2}$ content in the product stream drops, as part of the $\mathrm{CO}_{2}$ is hydrogenated to methane. When the $\mathrm{H}_{2} / \mathrm{CO}$ ratio exceed 3 , more $\mathrm{CO}_{2}$ is being consumed than produced. When the $\mathrm{H}_{2} / \mathrm{CO}$ ratio reached $4,40 \%$ of the $\mathrm{CO}_{2}$ in the original feed, plus all the $\mathrm{CO}_{2}$ that is produced in the $\mathrm{CO}$ hydrogenation, was consumed. The dry methane molar fraction in the product reached $68 \%$. These results allow us to point out some generic observations that could be implemented not only in our integrated system but also in similar configurations: (i) the efficiency of the shift reactor is key to maximize the $\mathrm{H}_{2} / \mathrm{CO}$ (ii) high $\mathrm{H}_{2} / \mathrm{CO}$ ratios (over 3 ) facilitate $\mathrm{CO}_{2}$ conversion via methanation, which is beneficial for the synthetic natural gas yield perspective and also for the overall $\mathrm{CO}_{2}$ emissions management (iii) understanding the competition between the simultaneous reactions is fundamental to achieve the best mass and energy integration.

\section{Conclusions}

Our work analyses a fairly new angle for the integration of coal-based methane production and OCM as an integrated route for ethylene production. Our results indicate that the design and optimization of the linking stream between OCM and methane production via coal gasification is the key parameter for a successful process integration. Overall, $\mathrm{CH}_{4}$ production has to be maximized and the $\mathrm{CO}_{2}$ contain adjusted to facilitate the downstream operations. In this sense, $\mathrm{CO}_{2}$ methanation is proposed as an extra source of methane which at the same permits the regulation of the $\mathrm{CO}_{2}$ levels in the linking stream. In order to maximize methane yield in the methanation reactor, low temperatures, high pressures and high hydrogen contents are the most suitable conditions. According to the simulation results, methane conversion was more sensitive to temperature than to pressure. This suggests that a trade-off low temperature/medium-low pressure can be reached facilitating the economic viability of the process.

Overall, our model opens new research avenues for the optimization of methane synthesis from coal and its coupling with the OCM-DRM reactions and could aid experimentalists dealing with the reaction engineering and catalytic aspects of natural gas and ethylene production.

\section{References}

H.R. Godini, S. Xiao, M. Kim, O. Görke, S. Song, G. Wozny, 2013, Dual-membrane reactor for the methane oxidative coupling and dry methane reforming: Reactor integration and process intensification, Chemical Engineering and Processing, 74, 153-164.

H. Godini, A. Gili, O. Görke, U. Simon, K. Hou, G. Wozny, 2014, Performance Analysis of a Porous Packed Bed Membrane Reactor for Oxidative Coupling of Methane: Structural and Operational Characteristics, Energy \& Fuels, 28, 877-890.

P. Graf, 2008, Combining Oxidative coupling and reforming of methane, Universiteit Twente, 2008.

Y. Zhu, A. O. Oyedun, M. Wang, E. Pahija, C. W. Hui , 2015, Modelling and optimization of a heat integrated gasification process, Computer Aided Process Engineering, 401-406. 